\title{
The tunicate metabolite 2-(3,5-diiodo-4-methoxyphenyl)ethan-1- amine targets ion channels of vertebrate sensory neurons
}

\author{
Noemi D. Paguigan+, Yannan Yan”, Manju Karthikeyan ${ }^{\S}$, Kevin Chase $^{\S}$, Jackson Carter ${ }^{\S}$, Lee S. Leavitt ${ }^{\S}$, \\ Albebson L. Lim, Zhenjian Lin†, Tosifa Memon^, Sean Christensen, Bo H. Bentzen, Nicole Schmitt”, \\ Christopher A. Reilly^, Russell W. Teichert ${ }^{\S}$, Shrinivasan Raghuraman`, ${ }^{\S}$ Baldomero M. Olivera ${ }^{\S}$, Eric W. \\ Schmidt ${ }^{\dagger} \star$ \\ †Department of Medicinal Chemistry, University of Utah, Salt Lake City, Utah 81112, United States \\ ‡Department of Biomedical Sciences, Faculty of Health and Medical Sciences, University of Copenhagen, Copenhagen \\ 2200, Denmark \\ §Department of Biology, University of Utah, Salt Lake City, Utah 81112, United States \\ ^Department of Pharmacology and Toxicology, University of Utah, Salt Lake City, Utah 81112, United States \\ *Corresponding authors: ews1@utah.edu, shrinivasan.raghuraman@utah.edu
}

Table of Contents

Supporting Materials and Methods

Supporting Figures .....................................................................................................................................................

Figure S1. Census of effects elicited by DIMTA $(2.5 \mu \mathrm{M})$ on different subsets of DRG neurons ........................56

Figure S2. Constellation pharmacology shows the effects of DIMTA on calcium and sodium channels in

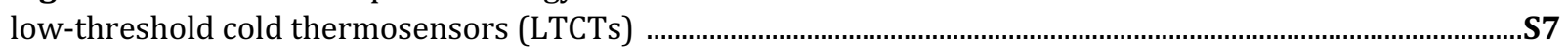

Figure S3. Inside-out recordings on hKca1.1 expressed in HEK-293 cells ........................................................... S8

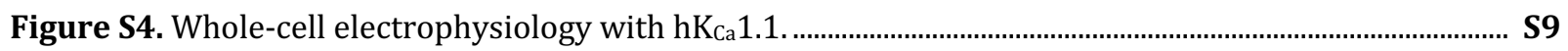

Figure S5. Effects of increasing concentrations of DIMTA on Kv11.1 expressed in HEK-293 cells .............. S10

Figure S6. Evaluation of DIMTA as an inhibitor of human transient receptor potential melastatin 8 (TRPM8) overexpressed in HEK-293 cells

Figure S7. Constellation pharmacology of DIMTA in dissociated VRC cells investigating its effect on dopamine receptors

Figure S8. Constellation pharmacology of DIMTA in dissociated VRC cells indicates that it does not affect adrenergic signaling ..... S13

Figure S9. Spectroscopic, spectrophotometric, and chromatographic analysis of DIMTA S14

Figure S10. DIMTA is widely distributed in tunicates collected from the Solomon Islands ...S15

Supporting Tables ...S14

Table S1. K channel genes (KCN) associated with TRPM8 expressing cells ...S14

Table S2. Raw data for in vivo cold plate assay S15

Supporting References. S15

\section{Materials and Methods}

Animals. The use of all animals followed protocols that were approved by the Institutional Animal Care and Use Committee of the University of Utah. To identify somatosensory neuronal subclasses in the calcium imaging 
experiments, calcitonin gene-related peptide (CGRP)-green fluorescent protein (GFP) transgenic reporter mice were used. Strain STOCK Tg(Calca-EGFP)FG104Gsat/Mmucd) was created by the Gensat project as previously described. ${ }^{1}$ In this mouse strain, GFP expression is driven by the gene regulatory elements of CGRP, which primarily labels peptidergic nociceptors in the somatosensory neuronal cell population. Male CD1 mice (20-30 g, 6-8 weeks old) obtained from Charles River Laboratories were acclimated for at least 5 days before the start of treatment for behavioral testing.

Cell culture. Preparation and culture of mouse dorsal-root ganglion (DRG) and ventral respiratory column (VRC) cells harvested from CGRP-GFP mice were described in detail previously. ${ }^{2,3}$ Human embryonic kidney 293 (HEK293) cells (ATCC) stably expressing human TRPM8 were cultured in Dulbecco's modified eagle's medium: Nutrient Mixture F12 Ham (DMEM:F12) media supplemented with 5\% FBS and Geneticin (300 $\mu \mathrm{g} / \mathrm{mL}$ ). HEK-293 and Chinese hamster ovary (CHO) cells were cultured in DMEM supplemented with $10 \% \mathrm{FBS}$ and $1 \%$ penicillin-streptomycin. All cells were cultured in an incubator maintained at $37{ }^{\circ} \mathrm{C}$ in a humidified atmosphere with $5 \% \mathrm{CO}_{2}$.

Expression constructs. Plasmids suitable for heterologous expression in Xenopus laevis oocytes and mammalian cells harboring the cDNAs of human Kv7.2 (KCNQ2, GenBank NM_004518) and $\mathrm{K}_{\mathrm{ca}} 1.1$. (KCNMA, GenBank NM_002247) have been described previously.4, 5 The plasmid carrying human Kv3.1 (KCNC1, GenBank NM_001112741.1) ${ }^{6}$ was a kind gift from Dr. Thomas Jespersen (University of Copenhagen, Denmark).

General chemical procedures. NMR data were collected using a Varian INOVA 500 spectrometer operating at $500 \mathrm{MHz}$ for ${ }^{1} \mathrm{H}$ and $125 \mathrm{MHz}$ for ${ }^{13} \mathrm{C}$, and equipped with $5 \mathrm{~mm}$ Varian $\mathrm{HCN}$ Oneprobe for proton detected experiments and a $3 \mathrm{~mm}$ Varian inverse probe for carbon detected experiments. NMR shift values were referenced to the residual solvent signals. UPLC-HRESI(+)-TOFMS analysis was performed on a Waters Acquity H class UPLC system coupled to a Waters Xevo G2-XS qTOF equipped with a Z spray ESI source. HPLC separations were performed using a Thermo Scientific ${ }^{\mathrm{TM}}$ Dionex ${ }^{\mathrm{TM}}$ Ultimate-3000 HPLC system equipped with a photodiode array detector. The purity of DIMTA was rigorously determined to be $>99 \%$ using UPLC-MS, HPLC-DAD, and NMR experiments. The amount of DIMTA used in pharmacology experiments was measured with high accuracy using a digital analytical balance (Mettler Toledo).

Collection, extraction of genomic DNA, and sequencing of phylogenetic markers. The tunicate Didemnum sp. was collected by hand using SCUBA in April 2018 (collection number SI-028S) from Solomon Islands (S 09 ${ }^{\circ}$ $6^{\prime} 51.11 \mathrm{E} 160^{\circ} 11^{\prime} 2.10$ ). Portions of the freshly collected sample were set aside for chemical analysis and preserved in RNAlater and were kept frozen at $-20^{\circ} \mathrm{C}$ until use. Genomic DNA was extracted from the RNAlater-preserved tissue of SI-028S using Genomic-tip (Qiagen). The mitochondrial COX1 gene was amplified from the genomic DNA using primers LC01490 (5'-GGT CAA CAA ATC ATA AAG ATA TTG G) and HCO2198 (5'-TAA ACT TCA GGG TGA CCA AAA AAT CA). ${ }^{7}$. The polymerase chain reaction was performed using a $50 \mu \mathrm{L}$ master mix consisting of $1 \mathrm{x}$ standard Taq buffer (New England Biolabs), LC01490 primer (0.2 mM), HCO2198 primer (0.2 mM), dNTP mix (200 $\mu \mathrm{M})$, Taq DNA Polymerase (1.25 U, New England Biolabs) and template DNA (10 ng/ $\mu \mathrm{L})$. PCR conditions were as follows: a hot start $\left(94{ }^{\circ} \mathrm{C}, 2 \mathrm{~min}\right.$ ) followed by 39 cycles of $\left[94^{\circ} \mathrm{C} / 30 \mathrm{~s}, 45^{\circ} \mathrm{C} / 30 \mathrm{~s}, 72^{\circ} \mathrm{C} / 2 \mathrm{~min}\right]$, then a final extension at $72{ }^{\circ} \mathrm{C}$ for 10 min. PCR product was purified using the QIAquick Gel Extraction Kit (Qiagen) and Sanger sequenced (Genewiz).

Isolation and purification of DIMTA. Frozen sample of SI-028S (wet weight, $50 \mathrm{~g}$ ) thawed, diced, and exhaustively extracted with $\mathrm{CH}_{3} \mathrm{OH}$. The resulting extract was filtered, dried in vacuo and subjected to reversed-phase HPLC using a Thermo Scientific ${ }^{\mathrm{TM}}$ Dionex ${ }^{\mathrm{TM}}$ WPS-3000 HPLC system equipped with a Photodiode array detector. The sample was purified using a Phenomenex Luna $\mathrm{C}_{18}$ column $(250 \times 10 \mathrm{~mm})$, eluting with an isocratic condition consisting of $30 \% \mathrm{CH}_{3} \mathrm{CN}$ in $\mathrm{H}_{2} \mathrm{O}(0.1 \% \mathrm{TFA})$ over $20 \mathrm{~min}$ at $3.5 \mathrm{~mL} / \mathrm{min}$ flow rate to yield a white amorphous powder identified as DIMTA (31 mg) by comparison of its ${ }^{1} \mathrm{H}$ NMR, ${ }^{13} \mathrm{C}$ NMR, and HRMS data with those previously reported (Figure S9). ${ }^{8,} 9$ The HPLC-purified compound (Figure S9) was dissolved in DMSO to obtain concentrated stock solutions $(12.5 \mathrm{mM})$ that were maintained frozen $\left(-20^{\circ} \mathrm{C}\right)$. The stock solutions were thawed and diluted to their final concentrations on the day of the experiments.

Single-cell transcriptomics analysis. As previously described, ${ }^{3}$ individual cells were picked using fire-polished glass pipettes with optimized diameter after completion of the constellation pharmacology experiments. Cells were lysed and mRNA was reverse transcribed to generate cDNA, which then underwent whole transcriptome amplification, all using the QIAseq FX Single Cell RNA library kit according to the manufacturer's standard protocol (Qiagen). The amplified cDNA was used to construct a sequencing library for the Illumina NGS platform, also using the QIAseq FX Single Cell RNA library kit. The amplified cDNA was fragmented to $300 \mathrm{bp}$ in size, treated for end repair and A-addition, followed by adapter ligation and then cleanup with Agencourt AMPure XP magnetic beads (Beckman Coulter Life Sciences). The cDNA library was submitted to the High Throughput Genomics Shared Resource, Huntsman Cancer Institute, for library quality control and sequencing. Sequencing data was analyzed using in house R scripts described before. ${ }^{3}$ 
Fluorometric calcium flux assay with HEK-293 TRPM8 overexpressing cells. Prior to calcium imaging experiments, the cells were seeded on a 96-well plate precoated with $1 \%$ gelatin, grown to confluence and incubated with the calcium indicator Fluo 4-AM (Fluo-4 Direct assay kit, Invitrogen) for $60 \mathrm{~min}$ at $37^{\circ} \mathrm{C}$. The loading solution was replaced with a wash solution comprising of LHC9 media (Life Technologies), $1 \mathrm{mM}$ probenecid, and $0.75 \mathrm{mM}$ trypan red (ATT Bioquest) $30 \mathrm{~min}$ before activity analysis. For inhibition assays the samples were supplemented with the wash solution and incubated for $30 \mathrm{~min}$. For agonist assays the samples were injected onto the cells preincubated with the wash solution. Changes in cellular fluorescence were monitored using a NOVOStar fluorescence plate reader (BMG Labtech). Data were normalized to the maximum change in fluorescence induced by TRPM8 agonist icilin $(50 \mu \mathrm{M})$. AMTB hydrochloride $(20 \mu \mathrm{M})$, a TRPM8 channel blocker, was used as a positive control in the antagonist assay. The IC ${ }_{50}$ value for the sample was calculated using nonlinear regression in GraphPad 7 (GraphPad Software).

Patch clamp experiments. To investigate the effects of DIMTA on Kv3.1 (isoform b), $0.6 \mu \mathrm{g} \mathrm{Kv} 3.1 \mathrm{~b}$ plasmid and $0.1 \mu \mathrm{g}$ eGPF were transfected into HEK-293 cells using Lipofectamine 2000 (Invitrogen Corporation), and recordings were performed after 3 days of incubation at $37^{\circ}$. The effects of DIMTA on $\mathrm{K}_{\mathrm{Ca}} 1.1$ and $\mathrm{K}_{\mathrm{v}} 11.1$ were studied using HEK293 cells and Chinese Hamster Ovary (CHO) constitutively expressing human $\mathrm{K}_{\mathrm{Ca}} 1.1$ and $\mathrm{K}_{\mathrm{v}} 11.1$, respectively.

For patch-clamp experiments, the cells were washed with PBS, detached from the culture flask using trypsin (ThermoFisher Scientific) or Detachin ${ }^{\mathrm{TM}}$ (Amsbio) and seeded onto glass coverslips for manual patch clamping or automatically loaded onto disposable single-hole Qplates (Biolin Scientific) for automated patch clamping. For Ka 1.1 inside-out experiments, the coverslips were coated with $50 \mathrm{mg} / \mathrm{L}$ poly-L-lysine at $37^{\circ} \mathrm{C}$ overnight in order to get better attachment of the cells to the coverslip. The coverslips were placed into a custom-made perfusion recording chamber with $\sim 1 \mathrm{ml} / \mathrm{min}$ continuous superfusion.

The recordings were performed at room temperature. Only cells that maintained a high membrane resistance seal above $1 \mathrm{G} \Omega$ and had a maximum serial resistance (Rs) of $10 \mathrm{M} \Omega$ were used for subsequent analysis. The serial resistance was compensated for 50 to $80 \%$ during the experiment. Data was acquired using a Multiclamp 700B amplifier (Axon Instruments). The analogue output signals were digitized and recorded after low pass filtering at 2.9 $\mathrm{kHz}$ through Digidata 1322A/1440A pClamp 10.2 (Molecular Devices). The patch-clamp borosilicate glass micropipettes were pulled by a horizontal DMZ universal puller (Zeitz Instruments). The electrodes had resistances between 1.5 and $3 \mathrm{M} \Omega$ when filled with solution.

The extracellular solution for all experiments contained: $\mathrm{NaCl}(145 \mathrm{mM}), \mathrm{CaCl}_{2}(2 \mathrm{mM}) \mathrm{MgCl}_{2}(1 \mathrm{mM}), \mathrm{KCl}(4 \mathrm{mM})$, glucose $(10 \mathrm{mM})$, and HEPES $(10 \mathrm{mM}), \mathrm{pH} 7.4$ adjusted with $\mathrm{NaOH}$. The intracellular solution contained: $\mathrm{CaCl}_{2}(5.17$ $\mathrm{mM}), \mathrm{MgCl}_{2}(1.42 \mathrm{mM}), \mathrm{KOH} / \mathrm{EGTA}(31.25 / 10 \mathrm{mM}), \mathrm{KCl}(114 \mathrm{mM}), \mathrm{KOH}(9 \mathrm{mM})$ and HEPES (10 mM), pH adjusted with $\mathrm{HCl}$ to 7.4 , resulting in a free calcium concentration of $100 \mathrm{nM}$.

$\mathrm{K}_{\mathrm{Ca}} 1.1$ currents. Kca1.1 currents were activated by ramping the membrane potential from $-80 \mathrm{mV}$ to $+50 \mathrm{mV}$ $(200 \mathrm{~ms}$ ) from a holding potential of $-80 \mathrm{mV}$. The protocol was repeated every $2 \mathrm{~s}$. The cell was stabilized for 1 to 5 min and then subjected to the following perfusion protocol: 1 min recording in extracellular solution (baseline); and 2 min in 1, 3, 10, 30, 100, $300 \mu \mathrm{M}$ DIMTA. In some experiments we switched back to the extracellular solution to observe if the effect of DIMTA could be washed off.

$\mathrm{K}_{\mathrm{v}} 3.1$ currents. To study the effect of DIMTA on Kv3.1 four different voltage protocols were applied. (1) IV protocol: the cells were held at $-80 \mathrm{mV}$ for $4800 \mathrm{~ms}$ followed by a $200 \mathrm{~ms}$ depolarizing pulses from $-80 \mathrm{mV}$ to +60 $\mathrm{mV}$ in $+10 \mathrm{mV}$ increments. (2) Online protocol: every $4^{\text {th }} \mathrm{s}$ the cells were activated to $+10 \mathrm{mV}$ for $100 \mathrm{~ms}$ from a holding potential of $-80 \mathrm{mV}$. (3) Inactivation protocol: the cells were held at membrane potentials between -100 to $-10 \mathrm{mV}$ for $30 \mathrm{~s}$, followed by a depolarization to $+40 \mathrm{mV}$. For each trial, the cell was held at $-80 \mathrm{mV}$ for $1 \mathrm{~min}$ to allow the ion channel to recovery from inactivation. (4) Instantaneous IV curve: to generate plots of the voltage dependence of activation (g/gmax) the reversal potential (Vrev) was established by depolarizing the cell membrane to $40 \mathrm{mV}$ for $200 \mathrm{~ms}$, followed by a voltage steps to -60 to -120 for $5 \mathrm{~s}$ in $5 \mathrm{mV}$ increments.

After stabilization of the $\mathrm{K}_{v} 3.1$ current the cells were subjected to the following perfusion protocol: $1 \mathrm{~min}$ recording in extracellular solution (baseline), and subsequently $2 \min$ in 1, 3, 10, 30, $100 \mu$ M DIMTA. During these perfusion periods the online voltage protocol was continuously applied. At the end of each perfusion period we ran the IV voltage protocol. Finally, in some cells, to investigate recovery from inhibition we switched back to extracellular solution.

In a separate set of experiments the effect of DIMTA on steady state inactivation was investigated. Following stabilization, the cells were subjected to the inactivation voltage protocol during normal extra cellular solution. We switched the solution to DIMTA, and once the effect of the compound had stabilized, we repeated the inactivation voltage protocol in the presence of the compound. 
Kv11.1 currents. We used the automatic patch clamp system QPatch-16 (Sophion) and disposable single-hole Qplates (Sophion) to investigate the effect of DIMTA on $\mathrm{K}_{\mathrm{V}} 11.1$ channels. The system allows for automatic giga seal formation, whole-cell formation, access resistance compensation, liquid application, and recording. CHO cells constitutively expressing Kv11.1 channels were held at $-90 \mathrm{mV}$ and currents activated by stepping to $+20 \mathrm{mV}$ from $80 \mathrm{mV}$ for $2 \mathrm{~s}$ and then to $-50 \mathrm{mV}$ for $2 \mathrm{~s}$ in order to record the tail current. The time between each depolarization was 7 s. Data were sampled at $10 \mathrm{kHz}$, four-order Bessel filter, cut-off frequency $3 \mathrm{kHz}$ and $70 \%$ Rs compensation. The perfusion protocol used was: baseline recordings in extracellular solution followed by application of increasing concentration of DIMTA $(3,10,30,60,100,300 \mu \mathrm{M})$.

Data analysis. For two-electrode voltage clamp, data were analyzed using the PatchMaster software (HEKA), and GraphPad Prism (GraphPad Software). Patch clamp data and automated patch clamp data were analyzed using Clampfit 10.7 software, QPatch software and GraphPad Prism. All values are expressed as means \pm SEM. All electrophysiological recordings were analyzed using one-way or two-way analysis of variance (ANOVA) followed by Tukey's or Sidak multiple comparison test. $p<0.05$ was considered significant.

IV and IV-peak curves were constructed from the IV protocol, and all data were plotted against the corresponding membrane potentials. The IV and IV-peak curves were constructed from measurements at the end of the depolarization and at the peak current amplitude, respectively.

Voltage dependence of activation was studied using normalized conductance (g/gmax) curves. These curves were generated from the I-V curves and the reversal potential (Vrev). The latter was experimentally found using the instantaneous IV voltage protocol. We calculated the conductance for each test potential using the formula: $\mathrm{G}=$ $\mathrm{I} /($ Vm- Vrev), where I is current amplitude and Vm is membrane potential. The resulting data were then fitted with a Boltzmann function: $\mathrm{g} / \mathrm{gmax}=1 /(1+\exp [-(\mathrm{V}-\mathrm{V} 1 / 2) / \mathrm{k}])$, where Gmax is the maximal conductance, $\mathrm{V}$ is the membrane potential, $\mathrm{V} 1 / 2$ is the potential at which the value of the relative conductance is 0.5 , and $\mathrm{k}$ is the slope factor.

To determine the voltage dependence of inactivation the peak current at $+40 \mathrm{mV}$ was normalized to the maximal $\mathrm{K}_{\mathrm{V}} 3.1$ current and plotted as a function of the preceding holding potential. The $\mathrm{V}_{50}$ of inactivation was determined by fitting a Boltzmann sigmoidal function to the individual inactivation curves.

The concentration-response curves were constructed by plotting the log(concentration) against the current density. Individual $\mathrm{IC}_{50}$ values for each experiment were calculated using the equation:

$$
Y=Y \min +\frac{(Y \max -Y \min )}{1+10^{X-\log I C 50}}
$$

where $\mathrm{X}$ is the $\log$ of concentration of DIMTA and Y is the measured current. The bottom a of the curve was constrained to 0 .

Estimation of indirect effects (IDE) in calcium imaging experiments with DRG neurons. IDE of the compound was estimated using repeated $15 \mathrm{~s}$ pulses of $\mathrm{K}^{+}(25 \mathrm{mM})$. Each pulse elicits a calcium response from all neurons in the experiment. The magnitude of the response was measured as the maximum area under the curve in any $15 \mathrm{~s}$ interval during incubation with $\mathrm{K}^{+}$(Kauc). This maximal response is highly reproducible for each cell. The deviation of this response after a 5-min incubation with each compound was used to estimate the indirect effect of the compound. A linear model ( $\operatorname{lm}$ function in $\mathrm{R}^{10}$ ) was applied to each neuron: $\operatorname{lm}($ Kauc $\sim \operatorname{linear}+\mathrm{c} 1+\mathrm{c} 2+\mathrm{c} 3+\mathrm{c} 4$ $+\mathrm{c5}$ )

Where Kauc is the statistic described above for each of the $16 \mathrm{~K}^{+}$pulses, linear is the sequential trend coded as sequential integers, $\mathrm{c} 1, \mathrm{c} 2, \mathrm{c} 3, \mathrm{c} 4$ and $\mathrm{c5}$ are indicator variables for the $\mathrm{K}^{+}$pulse that is under the influence of the specific compounds (DIMTA $(2.5 \mu \mathrm{M})$, DIMTA $(25 \mu \mathrm{M})$, TEA $(10 \mathrm{mM})$, nicardipine $(400 \mathrm{nM}), \mathrm{TEA}(10 \mathrm{mM})+$ nicardipine $(400 \mathrm{nM})$. The Tstat values from the coefficients matrix were taken as estimates of the magnitude and direction of IDE.

Estimation of direct effects (DE) in calcium imaging experiments with DRG neurons. DE of the compound was estimated by comparing the compound incubation interval to control interval incubations with only DRG observation buffer. The same statistics were calculated as detailed above. In this case the Tstat values from the linear regression are interpreted as the DE of the compound.

Estimating significance for multiple tests. Each experiment gave results for $500-1000$ neurons. To control for false positives and set appropriate thresholds for significance we used Monte Carlo simulations. The Tstats were estimated for all cells, recorded, and considered as the null distribution. The Tstat estimates from 100 Monte Carlo simulations were used to establish the thresholds for single test cell significance as well as whole experiment significance. The average 95\% interval from the 100 Monte Carlo simulations was used as the threshold for an individual cell. Cells that exceeded the lower bound were considered blocked. Those that exceeded the higher bound 
were considered amplified. The per-experiment significance was estimated as the fraction of Monte Carlo simulations that were different from the actual data at a ks.test threshold of 0.01 . The nature of the IDE is evident when comparing the actual Tstat distribution to the null distributions as empirical cumulative distribution function (ecdf) curves (Figure S1).

Associations Between Effects. Correlations between effects using the Tstats were estimated using the cor.test function of R.

Estimation of association between gene expression counts and cell TRPM8 class. Using single cell RNA seq data from DRG neurons, ${ }^{11}$ a logistic regression analysis was used to estimate the association between gene expression counts and cell TRPM8 class membership.

Metabolomics Analysis. UPLC-MS and MS/MS analyses of 192 tunicate specimens were done using an Agilent 6530 Q-TOF mass spectrometer with a Kinetex $C_{18}$ column $(2.6 \mu, 100 \mathrm{~A}, 100 \times 4.6 \mathrm{~mm}, 1 \mathrm{~mL} / \mathrm{min})$ and a gradient from 5 to $100 \% \mathrm{MeCN}$ in $20 \mathrm{~min}$. The raw LC-MS/MS data were converted to mgf format using MassHunter. The mgf version of the data was then submitted to molecular networking analysis using the GNPS web site. ${ }^{12}$ with the standard parameter and MSCluster option turned off. The output result was visualized using Cytoscape v3.7.13 


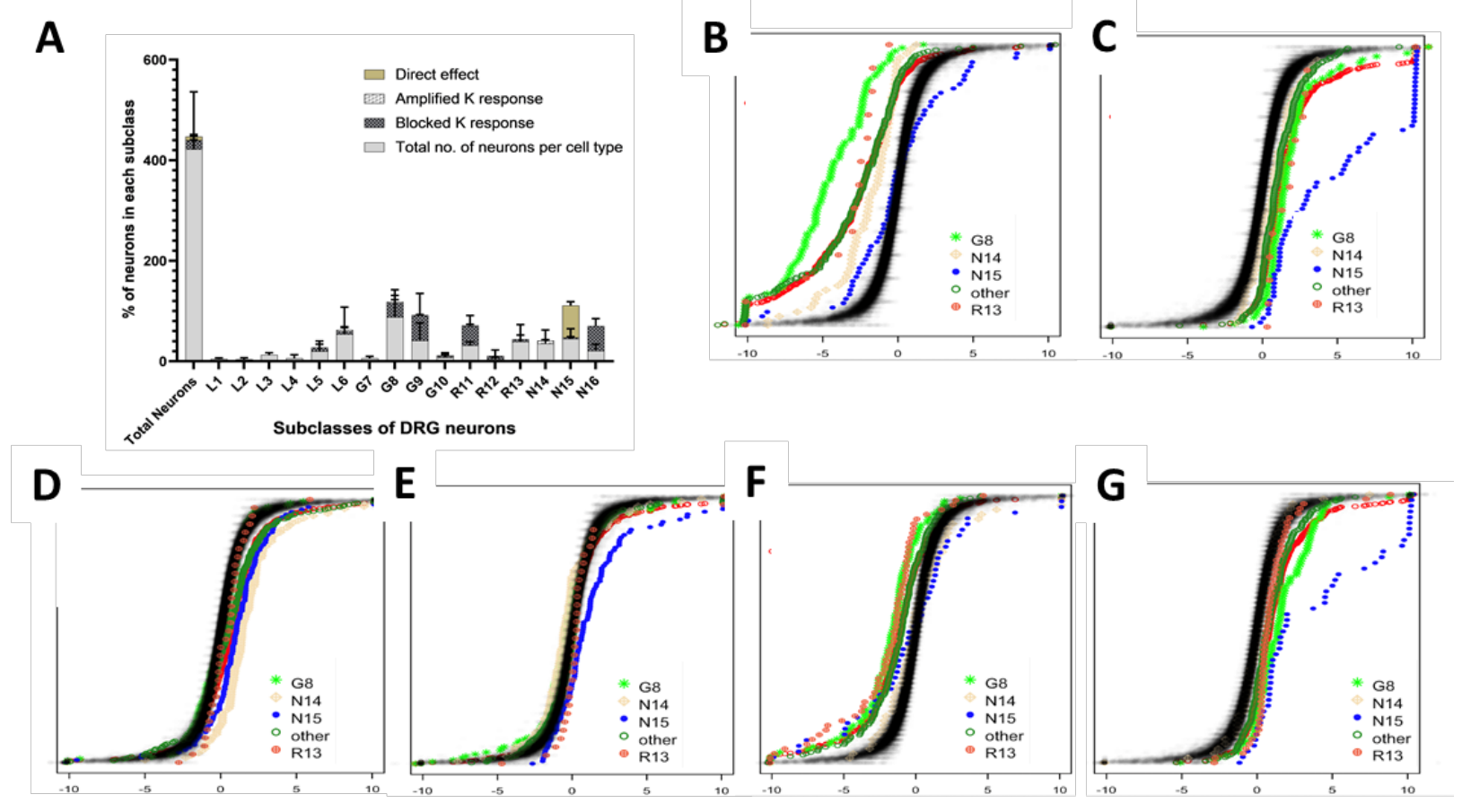

Figure S1. Census of effects elicited by DIMTA $(2.5 \mu \mathrm{M})$ on different subsets of DRG neurons. (A) Bar plot summarizing the effects of DIMTA in calcium imaging experiments $(\mathrm{n}=3)$. Block/amplification of the $\mathrm{Ca}^{2+}$ signal, or direct effects to the $\mathrm{Ca}^{2+}$ baseline with sample incubation were scored. The effects for each subtype (x-axis) are represented as the mean $\%$ of neurons in each subclass \pm standard deviation (y-axis). (B-G) Statistical analysis to estimate indirect (IDE, panels B, D and F) and direct effects (DE, panels C, E, G) for each calcium imaging experiment. The nature of the IDE and DE is compared to the actual Tstat distribution to the null distribution as empirical cumulative distribution function (ecdf) curves. The x-axis, the value of -10 to 10 indicates the IDEs block to amplification in (B), (D), and (F). For (C), (E), and (G) $x$-axis value $>0$ indicates DE. The $x$-axis value $=0$ indicates no effect. The $y$-axis indicates the relative number of cells that fall below the given value (ecdf), from 0 (bottom) to 1.0 (top). (B) IDE and (C) DE estimation in experiment 1. (D) IDE and (E) DE estimation in experiment 2. (F) IDE and (G) DE estimation in experiment 3. N15 represents the thermosensors while G8, N14, R13, and other are neurons belonging to different subclasses. 

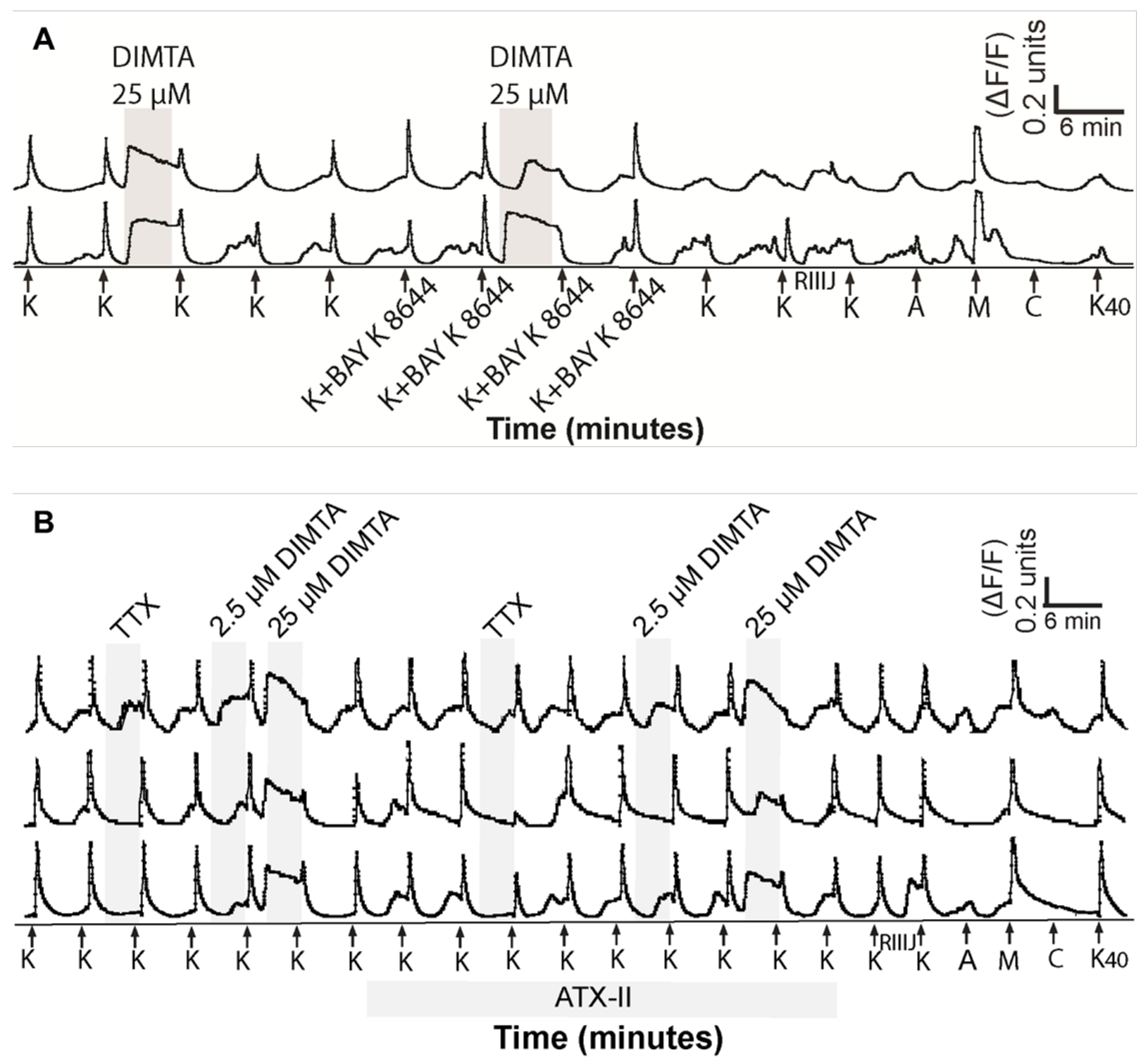

Figure S2. Constellation pharmacology shows the effects of DIMTA on calcium and sodium channels in low-threshold cold thermosensors (LTCTs). (A) and (B) represent constellation pharmacology using DIMTA. Each trace follows the Fura2-AM fluorescence min/max normalized ratio at 340/380 nm (a measure of relative intracellular calcium levels) $(y$-axis) of a single cell out of 500-1000 neurons in a single experiment. Chemicals were added over the experiment time ( $x$-axis), and the cellular responses were recorded. Arrows indicate 15-s application of potassium chloride $(\mathrm{K}$, $20 \mathrm{mM}$ ) or co-application of K and Bay K $8644(200 \mathrm{nM})$. The highlighted region indicates the period of DIMTA or pharmacological agent incubation. Sequential application of a set of pharmacological ligands was used to identify neuronal cell populations: K, RIIIJ $(1 \mu \mathrm{M})$, allyl isothiocyanate $(\mathrm{A}, 100 \mu \mathrm{M})$, menthol $(\mathrm{M}, 400 \mu \mathrm{M})$, and capsaicin $(\mathrm{C}$, $300 \mathrm{nM})$. Potassium chloride $40 \mathrm{mM}\left(\mathrm{K}_{40}\right)$ was applied at the end of the experiment to determine the viability of the neurons. (A) Selected traces from LTCTs illustrating the effects of DIMTA $(25 \mu \mathrm{M})$ on calcium $\left(\mathrm{Ca}^{2+}\right)$ channels. Bay K 8644 was co-applied with $\mathrm{K}$ to activate L-type $\mathrm{Ca}^{2+}$ channels. (B) Selected traces from LTCTs illustrating the effects of DIMTA $(2.5 \mu \mathrm{M}$ and $25 \mu \mathrm{M})$ and tetrodotoxin (TTX, $1 \mu \mathrm{M}$ ), a VGSC blocker. Anemonia viridis toxin 2 (ATX-II, 100 $\mathrm{nM}$ ) was applied to delay $\mathrm{Na}^{+}$channel inactivation. 
A
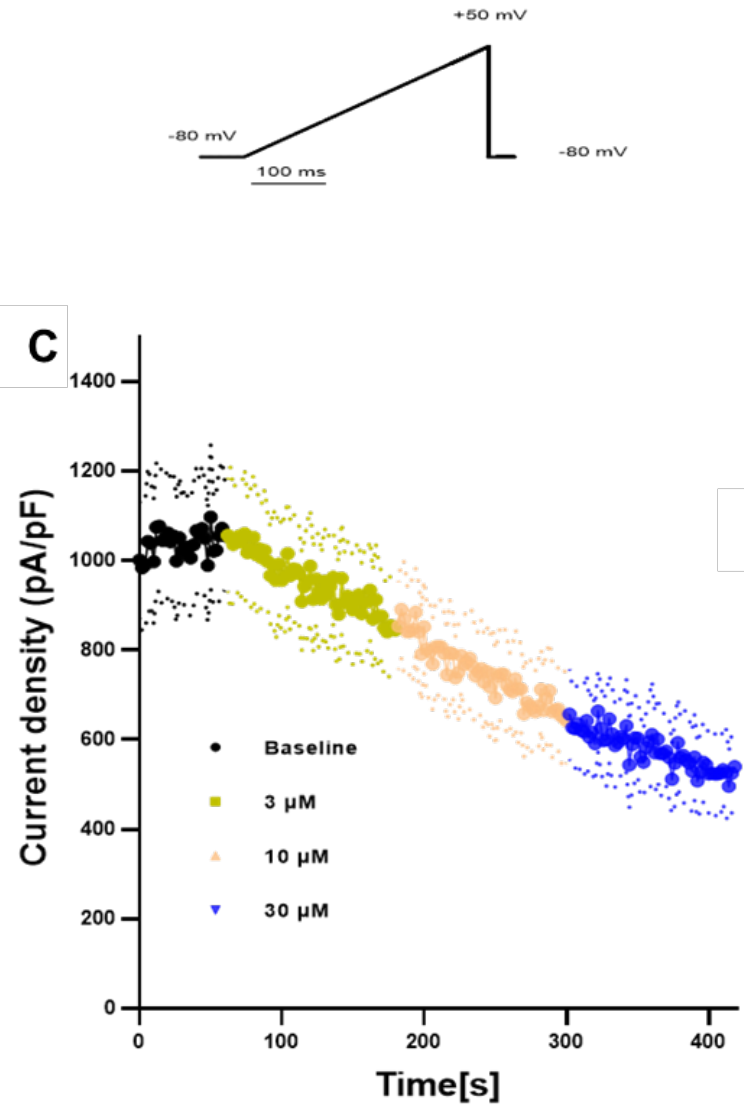

B

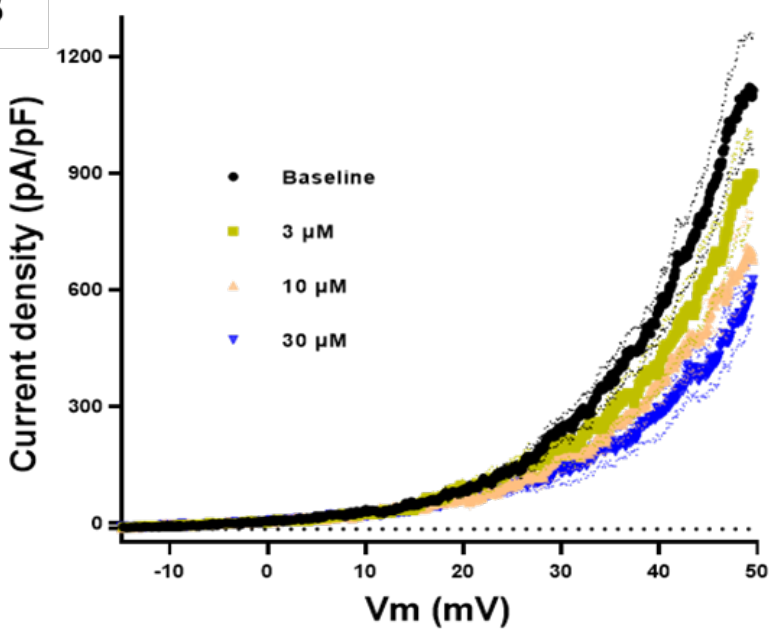

D

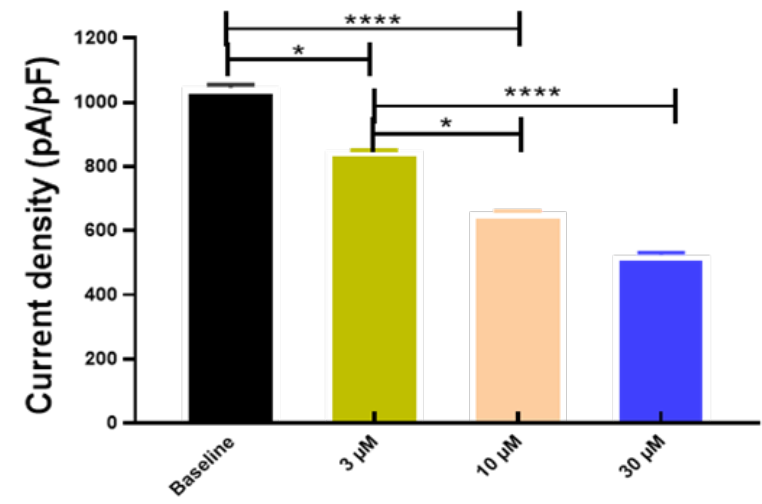

Figure S3. Inside-out recordings on $\mathrm{hK}_{\mathrm{Ca}} 1.1$ expressed in HEK-293 cells. (A) Currents were elicited every 2 s using the voltage-clamp protocol shown. (B) Mean current-voltage relationships and (C) current-time plots before and after application of increasing concentrations $(3 \mu \mathrm{M}, 10 \mu \mathrm{M}, 30 \mu \mathrm{M})$ of DIMTA. (D) Bar graph summarizing the effect of increasing concentrations of DIMTA on $\mathrm{K}_{\mathrm{Ca}} 1.1$ currents measured at $+50 \mathrm{mV}$. Data are presented as mean \pm SEM, $\mathrm{n}=10$. 
A

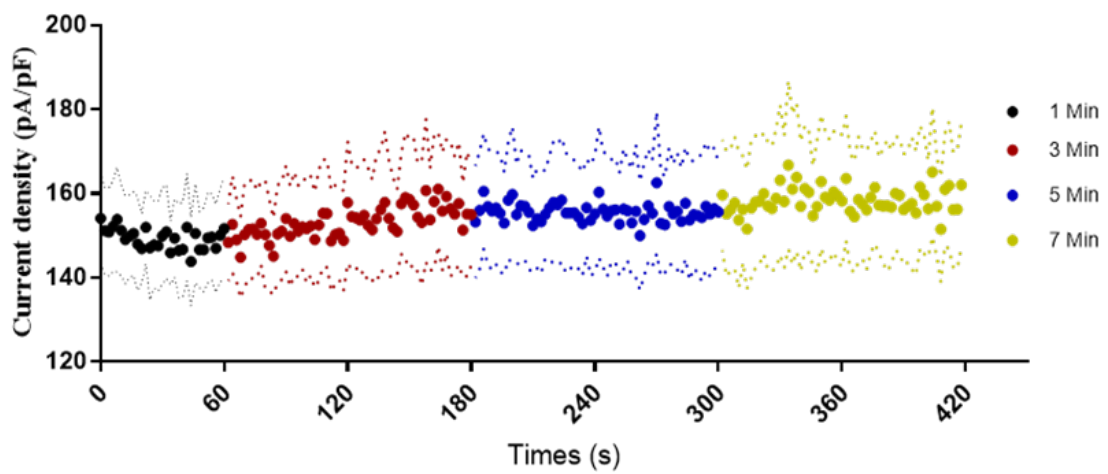

B

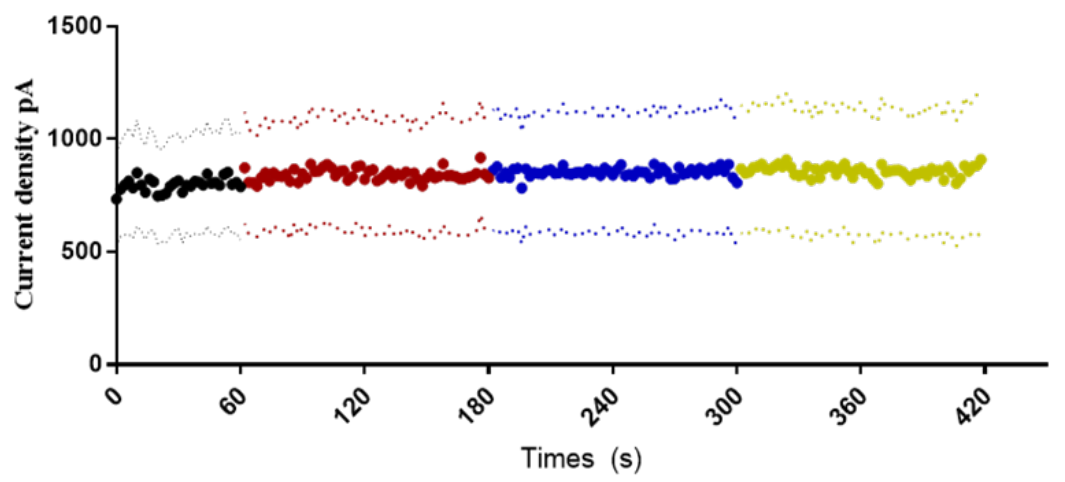

C
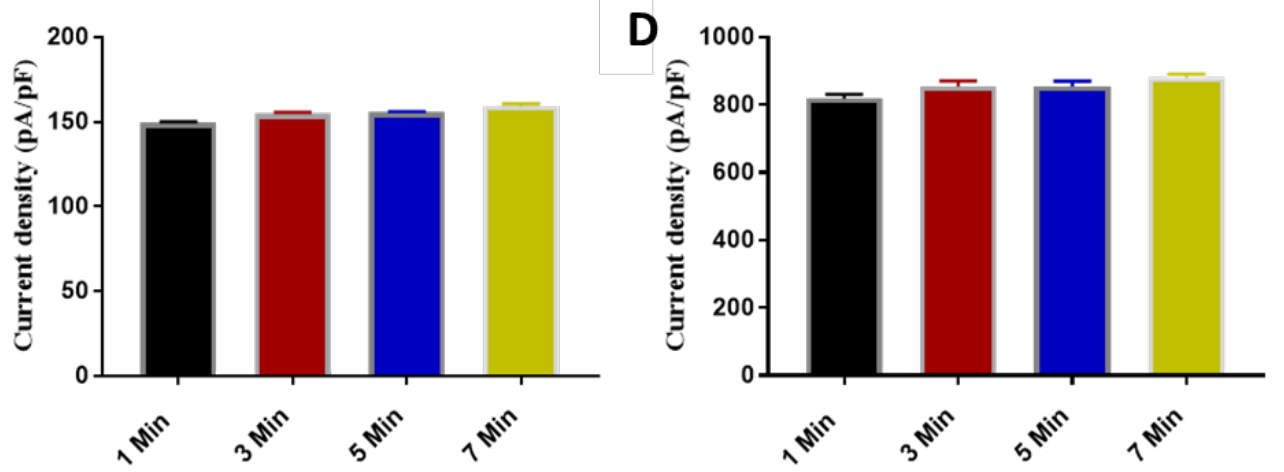

Figure S4. Whole-cell electrophysiology with $\mathrm{hK}_{\mathrm{Ca}} 1.1$. (A) Time matched control experiment on hK $\mathrm{K}_{\mathrm{Ca}} 1.1$ with wholecell configuration, $n=5$. (B) Time dependent control experiment of inside-out recordings of $\mathrm{K}_{\mathrm{Ca}} 1.1, \mathrm{n}=11$. (C) Bar graph summarizing the control experiment using $\mathrm{K}_{\mathrm{Ca}} 1.1$ with whole-cell configuration, currents measured at $+50 \mathrm{mV}$, bars represent mean $\pm \mathrm{SEM}, \mathrm{n}=5$. (D) Bar graph summarizing the control experiment using $\mathrm{K}_{\mathrm{Ca}} 1.1$ with inside-out configuration, currents measured at $+50 \mathrm{mV}$, bars represent mean $\pm \mathrm{SEM}, \mathrm{n}=11$. 

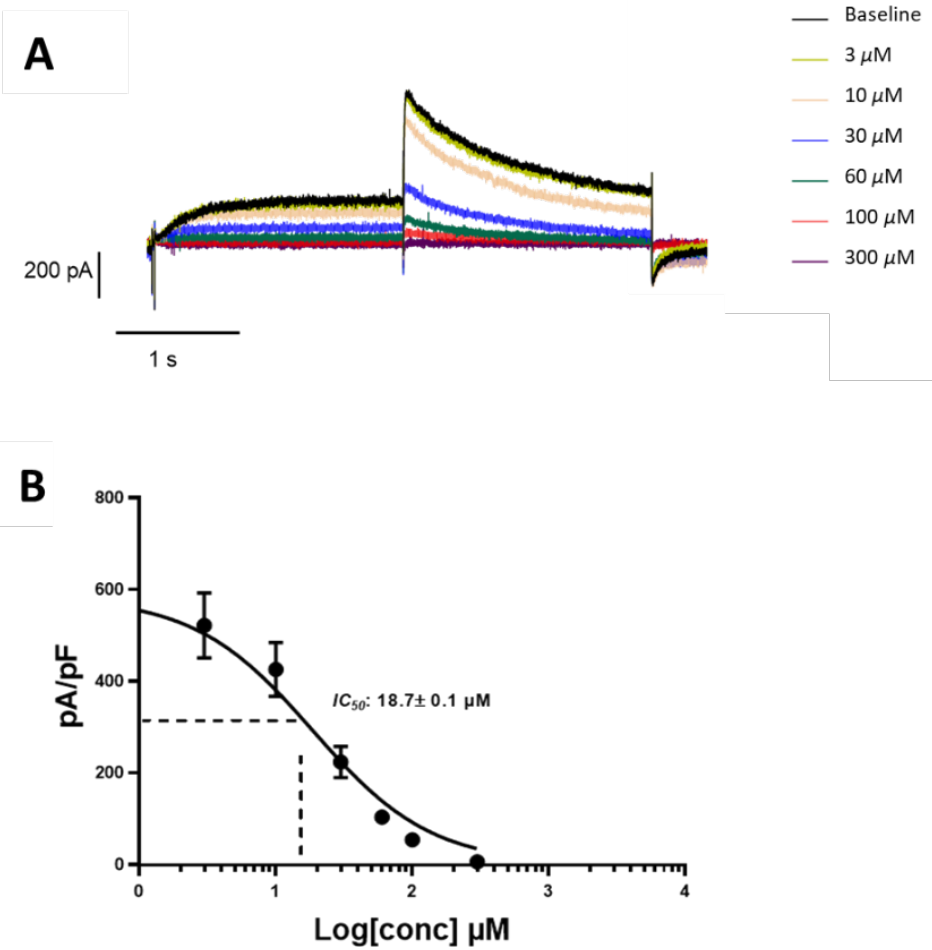

Figure S5. Effects of increasing concentrations of DIMTA on $\mathrm{K}_{v} 11.1$ expressed in HEK-293 cells. (A) Representative current recording of $\mathrm{K}_{\mathrm{V}} 11.1$ before and after application of increasing concentrations of DIMTA. (B) Concentration response relationship for DIMTA inhibition of Kv11.1 channel currents. Data are presented as mean \pm SEM, n=5-7. 

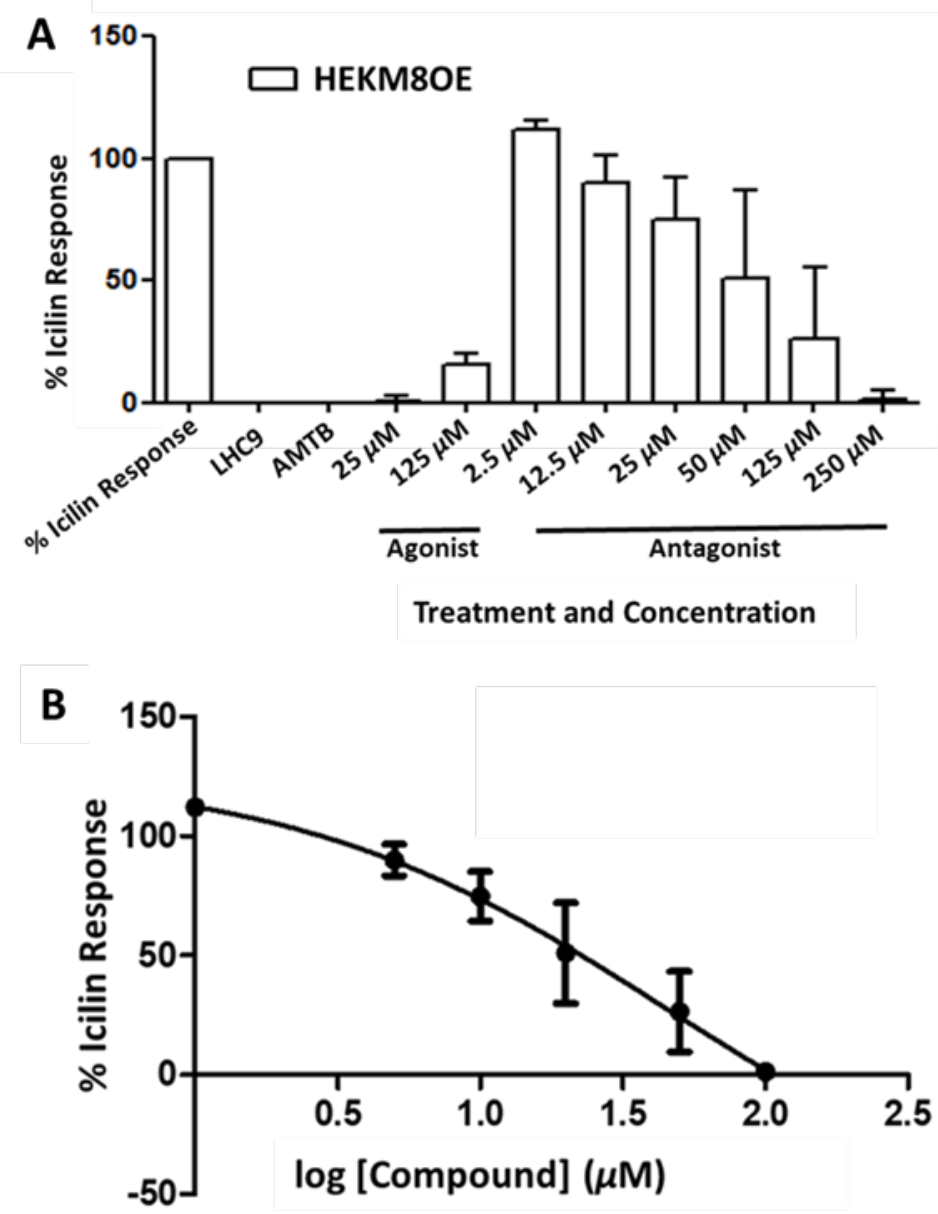

Figure S6. Evaluation of DIMTA as an inhibitor of human transient receptor potential melastatin 8 (TRPM8) overexpressed in HEK-293 cells. (A-B) Calcium flux in HEK-293 cells was induced by addition of icilin, a synthetic agonist of TRPM8. Data are normalized to the maximum fluorescence change elicited by the positive control $(50 \mu \mathrm{M}$ icilin). (A) Agonist and antagonist activity (x-axis) of DIMTA is normalized to icilin response and presented as \% Icilin response (y-axis). LHC9 is the media/buffer used in the calcium imaging assays. AMTB $(20 \mu \mathrm{M})$ is a commercially available TRPM8 antagonist. (B) The concentration response inhibition of hTRPM8 by DIMTA represented as \% Icillin Response (y-axis) vs log of DIMTA concentration (x-axis). Values are the mean \pm SEM from triplicate wells. The $\mathrm{IC}_{50}$ is $112 \mu \mathrm{M}$ with a Hill slope of -0.66 . 


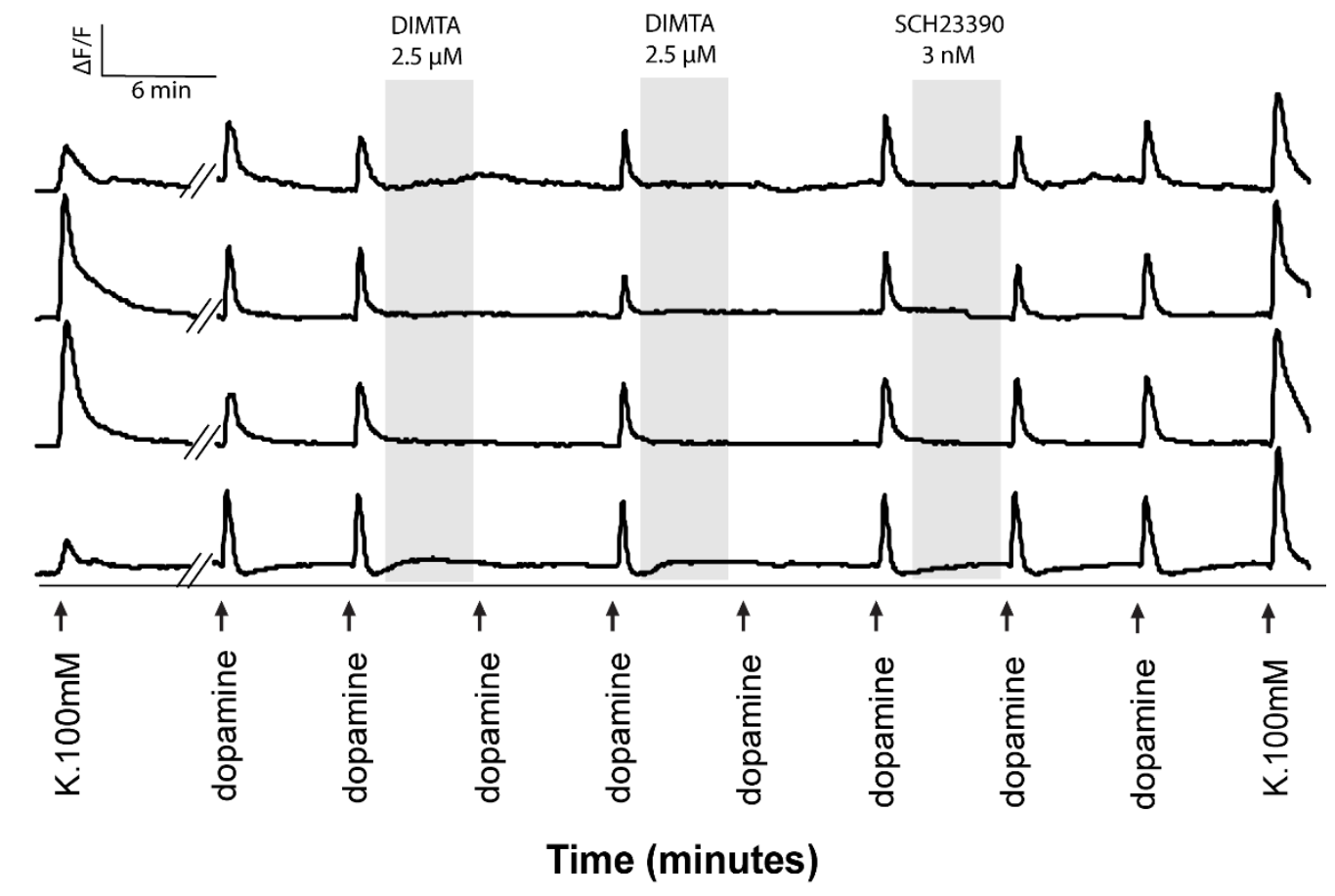

Figure S7. Constellation pharmacology of DIMTA in dissociated VRC cells investigating its effect on dopamine receptors. Shown above are representative individual VRC neurons responding to dopamine $(50 \mu \mathrm{M})$ in calcium imaging experiments $(\mathrm{n}=2)$. The $y$-axis indicates intracellular $\left[\mathrm{Ca}^{2+}\right]$, reflected as $340 \mathrm{nM} / 380 \mathrm{nM}$ fluorescence ratio from the Fura-2-AM Ca ${ }^{2+}$ indicator. The $x$-axis is time (min), where dopamine is repeatedly applied (arrows), with incubation of DIMTA $(2.5 \mu \mathrm{M})$ and dopamine receptor antagonist SCH $23390(3 \mathrm{nM})$. On average there were 835 VRC neurons, $<3 \%$ of these respond to dopamine. In general, DIMTA blocked all dopamine-elicited responses while SCH 23390 only partially blocked 14\% of these responses (top two traces). 


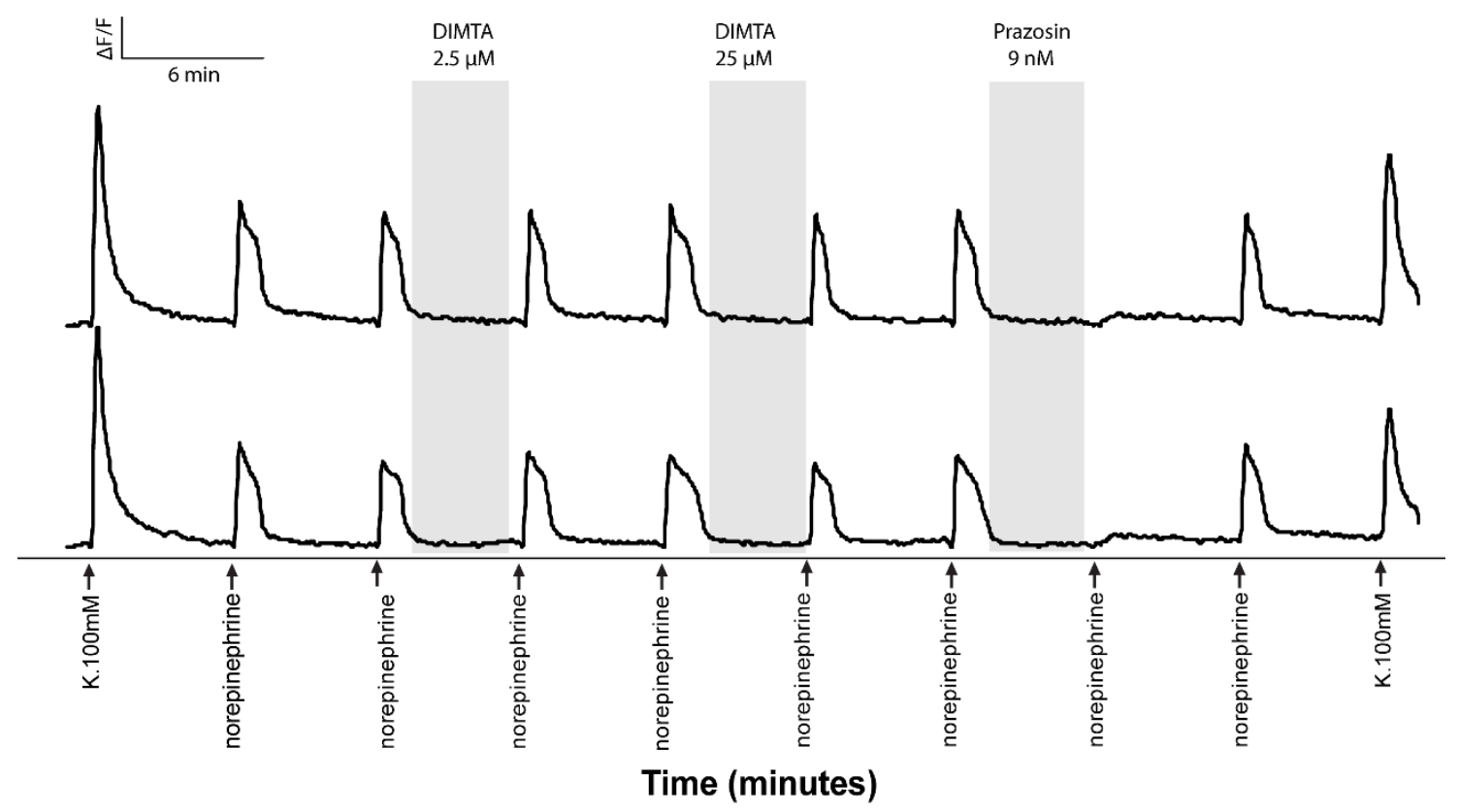

Figure S8. Constellation pharmacology of DIMTA in dissociated VRC cells indicates that it does not affect adrenergic signaling. Shown above are representative individual VRC neurons responding to norepinephrine (50 $\mu \mathrm{M})$. The $y$-axis indicates intracellular $\left[\mathrm{Ca}^{2+}\right]$, reflected as $340 \mathrm{nM} / 380 \mathrm{nM}$ fluorescence ratio from the Fura-2-AM $\mathrm{Ca}^{2+}$ indicator. The $x$-axis is time (min), where norepinephrine is repeatedly applied (arrows), with incubation of DIMTA $(2.5 \mu \mathrm{M}$ and $25 \mu \mathrm{M})$, and adrenergic receptor antagonist prazosin $(9 \mathrm{nM})$. In this experiment $63 \%$ of VRC neurons responding to norepinephrine were blocked by prazosin. 


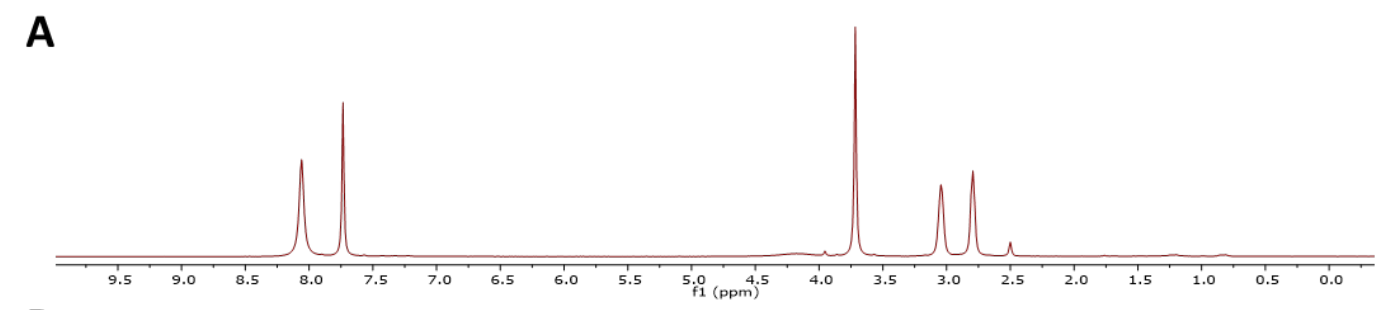

\section{B}
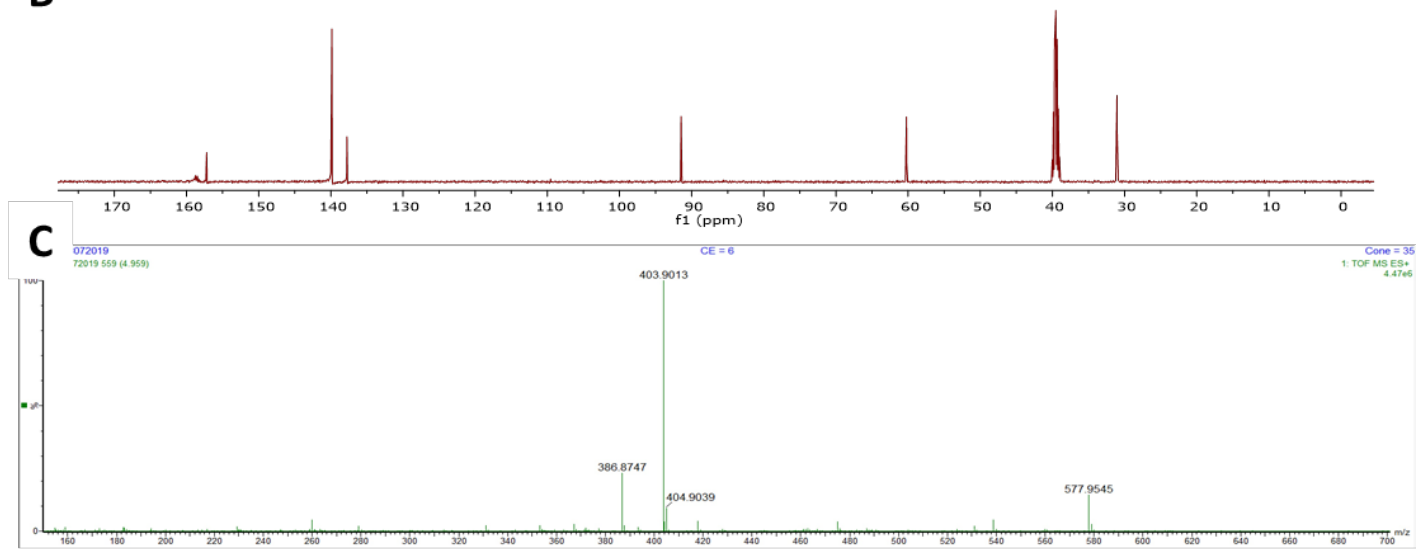

D

Single Mass Analysis

Tolerance $=5.0$ PPM / DBE: $\min =-1.5, \max =50.0$

Number of isotope peaks used for $\mathrm{i}-\mathrm{FIT}=3$

Monoisotopic Mass, Even Electron lons

3396 formula(e) evaluated with 4 results within limits (all results (up to 1000) for each mass)

$\begin{array}{llllll}\text { C: } 0-500 & \mathrm{H}: 0-1000 & \mathrm{~N}: 0-200 & \text { O: } 0-200 & 23 \mathrm{Na}: 0-1 & 1271: 0-2\end{array}$

$\begin{array}{ccc}1-211-4 \quad 08072019 & C E=6 & \text { Cone }=35 \\ 1-211-4 \_08072019559(4.959) & & 1: \text { TOF MS ES+ } \\ & 4.47 \mathrm{e}+006\end{array}$

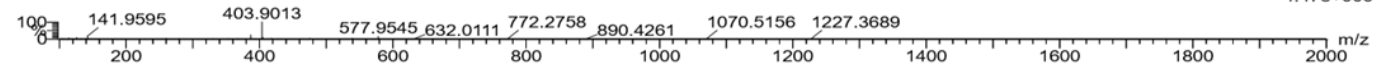

$\begin{array}{lll}\text { Minimum: } & & -1.5 \\ \text { Maximum: } & 5.0 \quad 5.0 & 50.0\end{array}$

Mass Calc. Mass mDa PPM DBE i-FIT Norm Conf $\left(\frac{8}{8}\right)$ Formula

$\begin{array}{llllllllll}403.9013 & 403.9008 & 0.5 & 1.2 & 3.5 & 709.7 & 0.002 & 99.85 & \text { C9 H12 N O } 127 \text { I2 } \\ & 403.9016 & -0.3 & -0.7 & 10.5 & 716.8 & 7.034 & 0.09 & \text { C10 H3 N3 O7 } 127 \text { I }\end{array}$

$\begin{array}{llllllll}403.9016 & -0.3 & -0.7 & 10.5 & 716.8 & 7.034 & 0.09 & \text { C10 H3 N3 O7 127I } \\ 403.9005 & 0.8 & 2.0 & 12.5 & 717.1 & 7.374 & 0.06 & \text { C9 N7 O3 } 23 N a 127 \text { I }\end{array}$

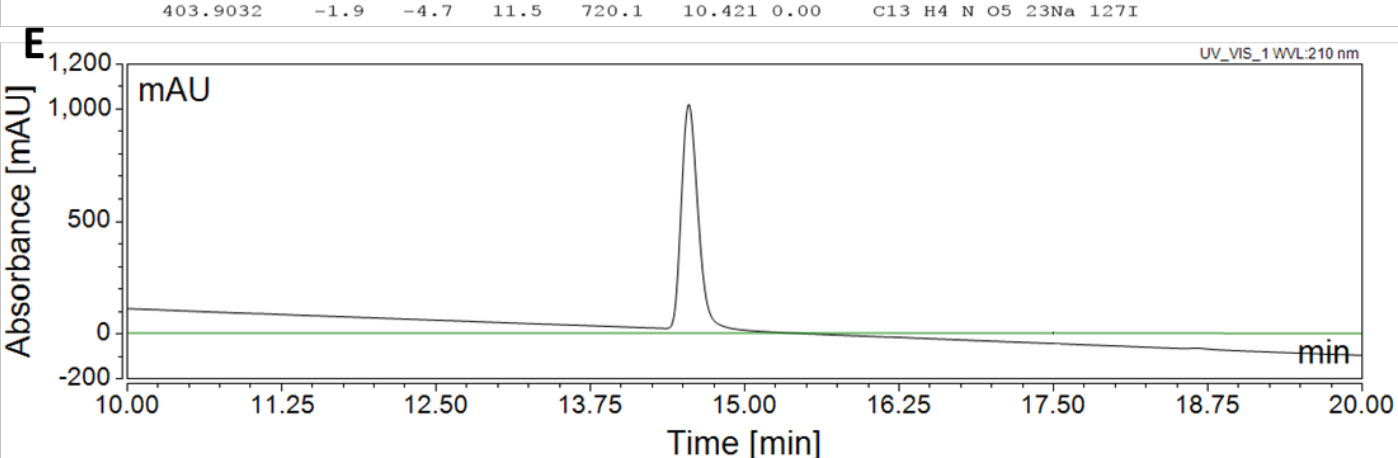

Figure S9. Spectroscopic, spectrophotometric, and chromatographic analysis of DIMTA. (A) ${ }^{1} \mathrm{H}$ NMR $(500 \mathrm{MHz})$ and (B) ${ }^{13} \mathrm{C}$ NMR (125 MHz spectra of DIMTA in DMSO-d $\mathrm{d}_{6}$ (C)-(D) (+)-HRESITOFMS of DIMTA showing m/z 403.9013 $[\mathrm{M}+\mathrm{H}]^{+}$(calculated for $\mathrm{C}_{9} \mathrm{H}_{12} \mathrm{NOI}_{2}{ }^{+}$, 403.9003). (E) Chromatographic profile of DIMTA using an analytical Eclipse Plus $\mathrm{C}_{18}$ column $(3.5 \mu \mathrm{m} ; 4.6 \times 150 \mathrm{~mm})$ and eluted with a linear gradient from $5 \%$ to $100 \% \mathrm{CH}_{3} \mathrm{CN}_{\text {in }} \mathrm{H}_{2} \mathrm{O}(0.1 \%$ TFA $)$ over $24 \mathrm{~min}$ at $0.5 \mathrm{~mL} / \mathrm{min}$ flow rate. The UV absorbance was monitored at $210 \mathrm{~nm}$. 


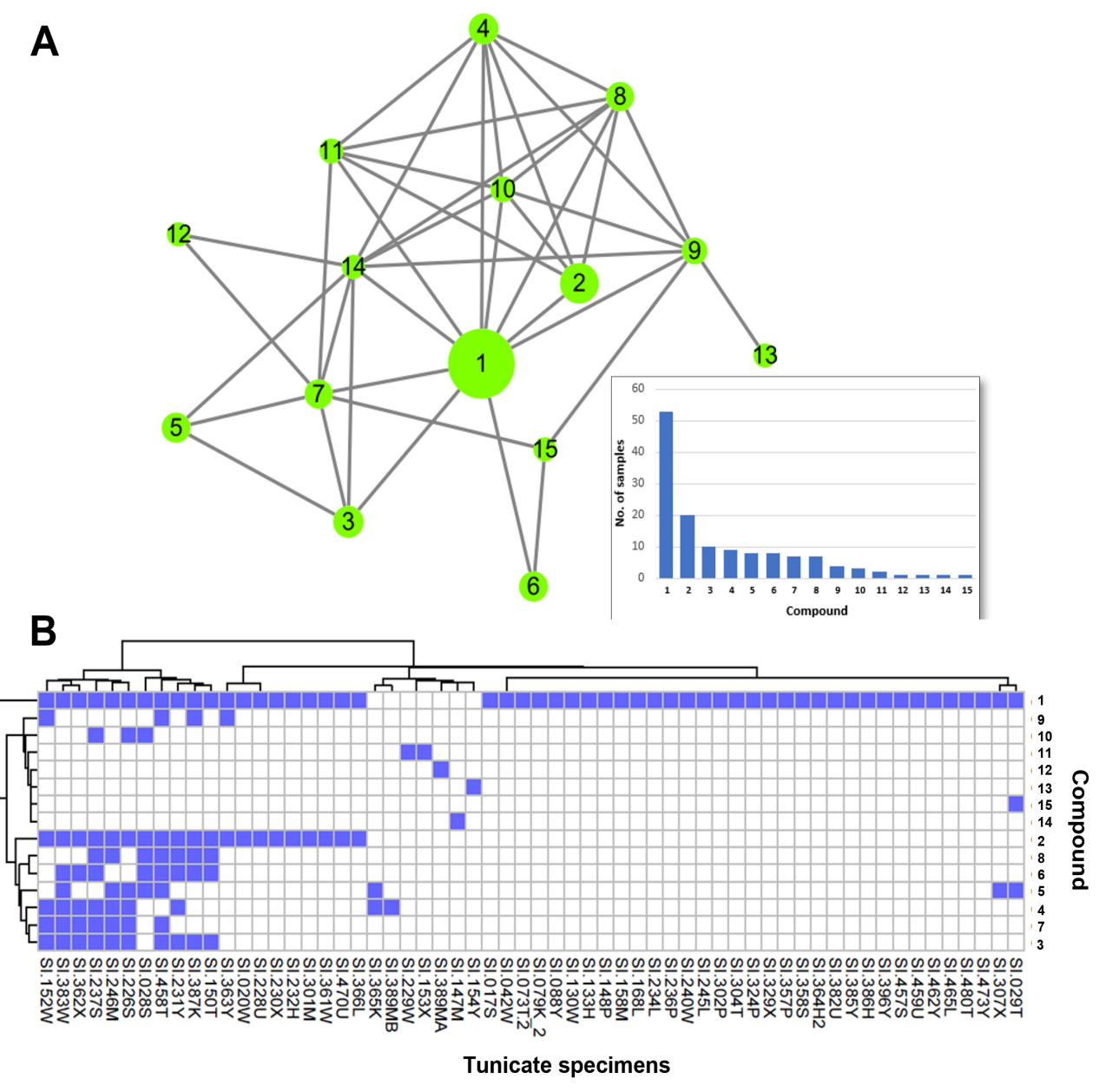

Figure S10. DIMTA is widely distributed in tunicates collected from the Solomon Islands. A) An MS/MS molecular network highlighting the presence of DIMTA and related metabolites identified by metabolomics analysis of 192 tunicates. Each numbered node represents a metabolite where DIMTA is represented as node 1 . The size of the nodes is proportional to the number (shown in the inset image) of tunicate specimens in which the compound is identified. B) Distribution of DIMTA shown in the network in panel A. A blue block indicates the presence of the compound in the sample based on HRESIMS data 
Table S1. K channel genes $(K C N)$ associated with TRPM8 expressing cells.

\begin{tabular}{|c|c|c|c|c|c|}
\hline Gene & Mean & glt.z & frac.0M8 & frac.1M8 & sLog10p \\
\hline KCNK2 & 0.992 & 18.7 & 0.290 & 0.750 & 92 \\
\hline KCNN3 & 0.022 & 22.5 & 0.009 & 0.213 & 89 \\
\hline KCNMB2 & 0.302 & 19.6 & 0.154 & 0.539 & 80 \\
\hline KCNK3 & 0.543 & 12.6 & 0.212 & 0.467 & 34 \\
\hline KCNN2 & 0.145 & 7.4 & 0.109 & 0.221 & 11 \\
\hline KCNMA1 & 0.631 & 6.9 & 0.378 & 0.535 & 11 \\
\hline KCNQ1OT1 & 0.641 & 6.8 & 0.401 & 0.557 & 11 \\
\hline KCNA2 & 1.751 & 6.4 & 0.611 & 0.756 & 10 \\
\hline KCNH8 & 0.087 & 6.9 & 0.069 & 0.154 & 10 \\
\hline KCNC2 & 0.696 & 6.2 & 0.389 & 0.531 & 9 \\
\hline KCNA4 & 0.536 & 4.3 & 0.352 & 0.447 & 5 \\
\hline KCNC4 & 2.397 & 4.1 & 0.568 & 0.662 & 4 \\
\hline KCNC1 & 0.385 & 4.1 & 0.221 & 0.301 & 4 \\
\hline KCND2 & 0.023 & 4.4 & 0.019 & 0.049 & 4 \\
\hline KCNH7 & 1.252 & 2.6 & 0.519 & 0.580 & 2 \\
\hline KCNAB2 & 7.182 & 0.1 & 0.989 & 1.000 & 2 \\
\hline KCNJ4 & 0.053 & 2.4 & 0.043 & 0.066 & 2 \\
\hline KCNB2 & 5.636 & 1.9 & 0.958 & 0.975 & 1 \\
\hline KCNQ2 & 0.568 & 1.6 & 0.349 & 0.383 & 1 \\
\hline KCNC3 & 0.299 & 0.1 & 0.218 & 0.219 & 0 \\
\hline KCNJ10 & 0.097 & -0.1 & 0.077 & 0.076 & 0 \\
\hline KCNH6 & 0.060 & -1.0 & 0.058 & 0.047 & 0 \\
\hline KCNAB3 & 0.014 & -1.3 & 0.013 & 0.006 & -1 \\
\hline KCNMB4OS & 0.112 & -1.4 & 0.099 & 0.080 & -1 \\
\hline KCNJ16 & 0.012 & -1.5 & 0.012 & 0.004 & -1 \\
\hline KCNJ12 & 0.471 & -1.4 & 0.290 & 0.260 & -1 \\
\hline KCNF1 & 0.044 & -1.5 & 0.041 & 0.027 & -1 \\
\hline KCNH2 & 0.240 & -1.5 & 0.164 & 0.139 & -1 \\
\hline KCNT1 & 1.265 & -16.1 & 0.582 & 0.061 & -127 \\
\hline KCNIP3 & 1.343 & -17.9 & 0.629 & 0.113 & -119 \\
\hline KCNAB1 & 1.438 & -12.7 & 0.470 & 0.031 & -103 \\
\hline KCNQ2 & 0.511 & -0.1 & 0.348 & 0.000 & -88 \\
\hline KCNA6 & 1.207 & -16.7 & 0.633 & 0.203 & -79 \\
\hline KCNMB1 & 1.056 & -10.5 & 0.376 & 0.020 & -79 \\
\hline KCNIP2 & 1.285 & -13.3 & 0.448 & 0.059 & -79 \\
\hline KCNH1 & 0.533 & -11.8 & 0.379 & 0.055 & -60 \\
\hline KCND1 & 1.574 & -15.6 & 0.698 & 0.332 & -59 \\
\hline KCND3 & 1.632 & -13.0 & 0.517 & 0.189 & -48 \\
\hline KCNN1 & 0.413 & -10.2 & 0.308 & 0.041 & -48 \\
\hline KCNK12 & 0.404 & -9.6 & 0.279 & 0.037 & -42 \\
\hline KCNQ5 & 0.301 & -6.8 & 0.199 & 0.008 & -39 \\
\hline KCNV1 & 0.244 & -4.5 & 0.152 & 0.002 & -32 \\
\hline KCNJ3 & 0.316 & -8.4 & 0.227 & 0.039 & -30 \\
\hline KCNS1 & 0.211 & -6.3 & 0.153 & 0.010 & -27 \\
\hline KCNT2 & 0.155 & -0.1 & 0.108 & 0.000 & -23 \\
\hline KCNK13 & 0.241 & -7.6 & 0.198 & 0.043 & -22 \\
\hline KCNA1 & 0.524 & -7.7 & 0.263 & 0.098 & -18 \\
\hline KCNK1 & 0.270 & -6.2 & 0.171 & 0.057 & -13 \\
\hline KCNIP1 & 0.146 & -5.7 & 0.120 & 0.027 & -13 \\
\hline KCNK10 & 0.058 & -3.3 & 0.055 & 0.002 & -10 \\
\hline KCNK18 & 0.084 & -4.6 & 0.075 & 0.010 & -10 \\
\hline KCNQ3 & 0.253 & -4.9 & 0.101 & 0.029 & -9 \\
\hline KCNS3 & 0.541 & -5.7 & 0.335 & 0.209 & -9 \\
\hline KCNG4 & 0.040 & -0.1 & 0.034 & 0.000 & -7 \\
\hline KCND3OS & 0.058 & -3.8 & 0.057 & 0.012 & -6 \\
\hline KCNJ2 & 0.038 & -2.9 & 0.036 & 0.002 & -6 \\
\hline
\end{tabular}

mean=mean expression across 11,139 cells

glt. $z=$ zscore from logistic regression onto binary TrpM8

frac. $0 M 8=$ fraction of cells expressing the gene $(>0)$ in TrpM8 negative cells

frac. $1 M 8$ = fraction of cells expressing the gene $(>0)$ in TrpM8 positive cells

sLog10p is signed $\log 10$ (fisher.test\$pvalue) 
Table S2. Raw data for in vivo cold plate assay.

\begin{tabular}{|c|c|c|c|c|c|}
\hline \multicolumn{2}{|c|}{ Vehicle* } & \multicolumn{2}{c|}{$\mathbf{1 ~ m g} / \mathbf{k g}$ DIMTA } & \multicolumn{2}{c|}{$\mathbf{1 0 ~} \mathbf{~ m g} / \mathbf{k g}$ DIMTA } \\
\hline Time (sec) & Temperature $^{\circ} \mathrm{C}$ & Time (sec) & Temperature ${ }^{\circ} \mathrm{C}$ & Time (sec) & Temperature ${ }^{\circ} \mathrm{C}$ \\
\hline 86.72 & 9.5 & 162.95 & 0.2 & 67.65 & 12.7 \\
\hline 72.07 & 12 & 101.93 & 7 & 156.59 & 0.2 \\
\hline 57.68 & 14.3 & 96.37 & 7.9 & 75.24 & 11.4 \\
\hline 78.35 & 10.9 & 89.97 & 9 & 139.6 & 1.4 \\
\hline 70.69 & 12.1 & 87.26 & 9.4 & 92.11 & 8.7 \\
\hline 104.37 & 6.7 & 141.3 & 1.1 & 144.38 & 0.5 \\
\hline 141.06 & 1.2 & 106.49 & 6.4 & 93.53 & 8.5 \\
\hline 109.01 & 6 & 87.91 & 8.3 & 168.88 & 0.3 \\
\hline 99.52 & 7.3 & 121.36 & 4.1 & 140.13 & 1.4 \\
\hline 105.06 & 6.6 & 141.79 & 1 & 107.94 & 6.1 \\
\hline 106.01 & 6.1 & 156.81 & 0.3 & 132.48 & 2.4 \\
\hline 111.22 & 5.6 & 89.94 & 9 & 108.89 & 6 \\
\hline 105.25 & 6.5 & 109.08 & 6 & 159.83 & 0.3 \\
\hline
\end{tabular}

*1\% DMSO in normal saline solution

\section{References}

(1) Gong, S., Zheng, C., Doughty, M. L., Losos, K., Didkovsky, N., Schambra, U. B., Nowak, N. J., Joyner, A., Leblanc, G., Hatten, M. E., et al. (2003) A gene expression atlas of the central nervous system based on bacterial artificial chromosomes. Nature 425, 917925.

(2) Raghuraman, S., Garcia, A. J., Anderson, T. M., Twede, V. D., Curtice, K. J., Chase, K., Ramirez, J. M., Olivera, B. M., and Teichert, R. W. (2014) Defining modulatory inputs into CNS neuronal subclasses by functional pharmacological profiling. Proc. Natl. Acad. Sci. U. S. A. 111, 6449-6454.

(3) Giacobassi, M. J., Leavitt, L. S., Raghuraman, S., Alluri, R., Chase, K., Finol-Urdaneta, R. K., Terlau, H., Teichert, R. W., and Olivera, B. M. (2020) An integrative approach to the facile functional classification of dorsal root ganglion neuronal subclasses. Proc. Natl. Acad. Sci. U. S. A. 117, 5494-5501.

(4) Bentzen, B. H., Schmitt, N., Calloe, K., Dalby Brown, W., Grunnet, M., and Olesen, S.-P. (2006) The acrylamide (S)-1 differentially affects Kv7 (KCNQ) potassium channels. Neuropharmacology 51, 1068-1077.

(5) Ljungstrom, T., Grunnet, M., Jensen, B. S., and Olesen, S.-P. (2003) Functional coupling between heterologously expressed dopamine D2 receptors and KCNQ channels. Pflugers Arch. 446, 684-694.

(6) Boddum, K., Hougaard, C., Xiao-Ying Lin, J., von Schoubye, N. L., Jensen, H. S., Grunnet, M., and Jespersen, T. (2017) Kv3.1/Kv3.2 channel positive modulators enable faster activating kinetics and increase firing frequency in fast-spiking GABAergic interneurons. Neuropharmacology 118, 102-112.

(7) Folmer, O., Black, M., Hoeh, W., Lutz, R., and Vrijenhoek, R. (1994) DNA primers for amplification of mitochondrial cytochrome c oxidase subunit I from diverse metazoan invertebrates. Mol. Mar. Biol. Biotechnol. 3, 294-299.

(8) Solano, G., Motti, C. A., and Jaspars, M. (2009) New iodotyramine derivatives from Didemnum rubeum. Tetrahedron 65, 74827486.

(9) Sesin, D. F., and Ireland, C. M. (1984) lodinated phenethylamine products from a didemnid tunicate. Tetrahedron Lett. 25, 403404.

(10) R Core Team (2021) R: A language and environment for statistical computing. R foundation for statistical computing, Vienna, Austria. URL https://www.R-project.org/.

(11) Sharma, N., Flaherty, K., Lezgiyeva, K., Wagner, D. E., Klein, A. M., and Ginty, D. D. (2020) The emergence of transcriptional identity in somatosensory neurons. Nature 577, 392-398.

(12) Wang, M.,Carver, J. J.,Phelan, V. V.,Sanchez, L. M.,Garg, N.,Peng, Y.,Nguyen, D. D.,Watrous, J.,Kapono, C. A.,Luzzatto-Knaan, T., et al. (2016) Sharing and community curation of mass spectrometry data with Global Natural Products Social Molecular Networking. Nat. Biotechnol. 34, 828-837.

(13) Shannon, P., Markiel, A., Ozier, O., Baliga, N. S., Wang, J. T., Ramage, D., Amin, N., Schwikowski, B., and Ideker, T. (2003) Cytoscape: a software environment for integrated models of biomolecular interaction networks. Genome Res. 13, $2498-2504$. 